\title{
IV Encuentro de Profesorado de Ciencias de la Salud y XI Jornadas de Docencia de Medicina
}

Bajo el epígrafe "Una respuesta del ámbito de las Ciencias de la Salud al reto del Espacio Europeo de Educación Superior" se ha convocado el IV Encuentro de Profesores de Ciencias de la Salud, en esta ocasión entroncado con las XI Jornadas de Docencia de Medicina que se celebran periódicamente en la Facultad de Medicina de la Universidad de Barcelona.

Una vez más se pone de manifiesto la voluntad de los profesores de Ciencias de la Salud de poner en común sus experiencias docentes y contextualizarlas en la época y ámbito en que van a desarrollar su profesión los futuros profesionales que reciben su formación en la Universidad.

Transcurrida casi una década del Primer Encuentro, los planteamientos evolucionan al ritmo de nuestro entorno, cada día más diverso desde el punto de vista sociológico, cada vez mas circunscrito a las normativas europeas, y con la mirada puesta, por parte de profesores y alumnos, en un ámbito global.

Sin embargo, no es difícil visualizar que subyacen en los nuevos planteamientos viejos temas recurrentes.

Así, durante el período 1868-1874 se vivió una vida universitaria intensa, especialmente en Madrid y Barcelona. "Se arrinconó, en cierto modo el libro de texto y el programa, fijados hasta entonces por el Consejo de Instrucción Pública, y los sistemas rutinarios, dando lugar a una mayor libertad metodológica y programática. De acuerdo con el espíritu de los tiempos, se intenta mantener la neutralidad política y religiosa de la Universidad “... "Se observa también un interés por adoptar algún cambio en el sistema de oposiciones y por vincular la Universidad a la vida social", según indica Jordi Monés, en el libro "L'aportació de la Universitat Catalana a la Ciència i a la Cultura" (Ed. L'Avenç, 1981)”.

Como decíamos anteriormente, viejas ideas recurrentes que no siempre han podido fructificar.

El entorno académico hay que considerarlo también, en el entorno social, y mas allá del enfoque didáctico y metodológico, debe orientar los contenidos para permitir a los licenciados ubicar sus conocimientos en el ámbito de sus competencias y del entorno humano en que deben ejercerlas.
Así, en cuanto a la enfermedad, la medicina, los medicamentos y las terapias, el entorno cultural es de una gran relevancia.

Según F. Guerra (Las medicinas marginales, 1976) "El ámbito cultural en que se desarrolla la enfermedad está íntimamente relacionado con la dinámica de las medicinas marginales, porque cada individuo, cada cultura, se enferma a su manera". Según el mismo autor, "Las medicinas tradicionales se adaptan mejor a los componentes psicosomáticos de cada cultura que la medicina científica". De ahí concluye que "las medicinas marginales, en cuanto utilizan métodos curativos tradicionales, complementan los objetivos de la medicina oficial", y también indica que "varios de los sistemas marginales peculiares de los centros urbanos y de las formas de subcultura de protesta se adaptan mejor que la medicina oficial a las necesidades espirituales de estos grupos"

Estas y otras muchas consideraciones impulsaron a los comités organizador y científico a plantear este encuentro entorno a los temas básicos siguientes:

Ámbito académico: programa de formación del profesorado hacia la integración europea, haciendo hincapié en las competencias transversales y específicas y en su evaluación.

Ámbito profesional, en el que se incide en la necesidad de conocimientos que el entorno cultural y sociológico genera en el profesional sanitario y se cuenta con la colaboración de los colegios profesionales para dialogar acerca de los perfiles profesionales y las competencias académicas.

Los miembros de los Comités Organizador y Científico queremos agradecer el apoyo institucional de nuestra Universitat de Barcelona, en particular del Sr. Rector, Màrius Rubiralta y del Vicerrector de Política Académica, Artur Parcerisa y de la Vicerrectora de Política Docente, Rosa Nonell. Asimismo al Instituto de Ciencias de la Educación, a los Decanos y Directores de las Facultades y Escuelas Universitarias de Ciencias de la Salud de la Universitat de Barcelona, que han prestado su apoyo, en especial a. $\mathrm{M}^{\mathrm{a}}$ Teresa Estrach, Presidenta del Comité Organizador y Decana de la Facultad de Medicina, que acoge este evento.

Queremos agradecer también muy especialmente 
a la Generalitat de Catalunya la presencia, en el acto inaugural, de la Consellera de Salut, Sra. Marina Geli, de la Comissionada per a Universitats i Recerca, Blanca Palmada, del Director General de Recursos Sanitaris, Rafael Manzanera y al Subdirector General de Especialidades en Ciencias de la Salud, José Ignacio Fuentes.

Finalmente, dar también las gracias a los Presidentes de los Colegios Profesionales por su presencia y participación, a las empresas y particulares que han dado su apoyo a este acontecimiento y a las asociaciones colaboradoras: ADMES -Barcelona, GDP-Farmacia, SEDEM, SCB, SAE, ACEM, Ass. Dietistes.
El número de profesores inscritos, la relevancia de los ponentes y el número de trabajos presentados, nos hacen predecir que la participación en las distintas sesiones y en los debates consecuentes será amplia y de gran utilidad para todos.

Esperamos que, si según P. Coelho "cuando una persona desea realmente algo, el Universo entero conspira para que pueda realizar su sueño", el deseo de todos los profesores de que este encuentro sea útil, provechoso y un foro de diálogo abierto a todas las opiniones, se cumpla para bien de todos.

Coloma Barbé Rocabert Vicepresidenta del Comité Organizador 